Article

\title{
Body Esteem among Korean Adolescent Boys and Girls
}

\author{
Sukkyung You ${ }^{1}$ (1) and Kyulee Shin ${ }^{2, *}$ \\ 1 College of Education, Hankuk University of Foreign Studies, Seoul 02450, Korea; skyou@hufs.ac.kr \\ 2 College of Liberal Arts \& Science, Anyang University, Kyeonggido 14028, Korea \\ * Correspondence: kyuleeshin@anyang.ac.kr
}

Received: 27 February 2019; Accepted: 31 March 2019; Published: 6 April 2019

\begin{abstract}
Establishing a positive body image is a critical factor for adolescents' physical and mental health as it leads to sustainable individual growth and development throughout their lives. Therefore, possible personality traits need to be examined for their capability as protective factors for a healthy body image. The current study examined how one internal personality trait (self-concept clarity) and three external factors (tripartite influence from media, parents, and peers) are associated with adolescents' internalization of the thin-body ideal and body esteem in a sample of Korean adolescents ( $N=1127)$. Self-concept clarity was identified as a powerful factor that is positively related with body esteem. The results showed that greater self-concept clarity, lower tripartite influences and thin body internalization were related to greater body esteem. Gender differences were found in the relationships between body esteem and the predictor variables. The implications of the findings and future research directions are discussed.
\end{abstract}

Keywords: self-concept clarity; thin body idealization; tripartite influence; body esteem; Korean adolescents

\section{Introduction}

Since adolescents undergo rapid physical changes with secondary sexual characteristics and thus need new body images, they are more highly subject to social pressure with regard to their body image than other age groups [1,2]. That is, adolescents going through rapid physical changes rely more easily on others' evaluation of their body and appearance than on their own and, therefore, they are highly sensitive to the body image required by society. Indeed, a number of previous studies reported that the tripartite influence of media, family, and peers, and comparison with others enforce adolescents' internalization of the thin-body ideal and increase their body dissatisfaction [2-5]. A previous study comparing US and Korean middle school students found that Korean girls reported greater body dissatisfaction than US girls [6-8]. Additionally, Korean youths with a low level of body dissatisfaction were likely to exhibit a low level of self-esteem and a high level of depressive symptoms $[2,9,10]$. Consequently, research has been conducted to identify the causes of body dissatisfaction leading to adolescents' mental problems, to develop diverse intervention strategies (e.g., exercises and cognitive behavior strategy programs), and to test the effects of such strategies.

Nevertheless, recent studies on positive body image from the perspective of positive psychology indicate that lowering body dissatisfaction does not necessarily increase positive body recognition or body esteem [11-13]. That is, positive body image and body dissatisfaction are two separate concepts [14] and, thus, identifying the cause of body dissatisfaction and conducting relevant intervention programs do not actually improve positive body image. Therefore, in order to establish a positive body image, it is necessary to explore and make use of factors that affect positive body recognition, body satisfaction, and body esteem. Wood-Barcalow, Tylka and Augustus-Horvath [15] 
defined positive body image as having self-confidence, body value, respect, acceptance, and affection toward one's own physical appearance and abilities. On the other hand, body esteem refers to self-perception [16] and self-evaluation [17-19] that encompass multi-dimensional concepts including one's emotions, attitudes, and feelings toward one's own body and appearance. This concept is equivalent to that of body satisfaction, or satisfaction with one's own body. Body esteem was defined in Kim and Kim [20] as a concept relevant to positive body image, with which one positively accepts the emotions caused by one's subjective perception and evaluation of one's own body, and values and loves one's body.

Body esteem is formed and changes complexly with diverse social and psychological influences. Among such external factors, the sociocultural pressure on body image resulting from parents, media, and peers (tripartite influence) has been investigated by numerous researchers [2,21,22]. Their studies reported that the influence of significant others on body image exerted negative effects on individuals' perception and internalization of body image, as well as on overall satisfaction with their bodies, directly and indirectly. The effect of the media, in particular, was shown to have a negative impact across gender and age groups, including middle school, high school, and college students [23-27]. A recent study showed that Korean female high school students tend to internalize the social standard of ideal beauty presented by the mass media $[2,28,29]$.

The establishment of body esteem is associated with the psychological mechanism of self-concept, which is now considered a complex concept consisting of structural (e.g., self-concept clarity) and content-evaluative (e.g., self-esteem; positive or negative judgment of oneself) aspects. Apart from the question of how well an individual's self-concept matches him or herself, self-concept clarity [30,31] refers to how clearly one can define oneself and how consistent and stable such a definition remains over time [30-32]. Therefore, people with a clear self-concept have consistent internal criteria and concepts of themselves, a clear identity and are less subject to external criteria [33]. In contrast, those with a less clear self-concept tend to rely on external criteria to establish their identity.

Only a few studies have investigated the self-concept clarity in the body image research area. Studies on young females [33-36] reported that low self-concept clarity enhanced the internalization of the thin ideal, consequently raising body dissatisfaction. Jeon [37] also found that the sociocultural pressure and self-concept clarity exerted significant influence on the internalization of the thin ideal among Korean female college students, so that females with low self-concept clarity frequently display comparative behavior related to their appearance and stronger internalization of the thin ideal.

Previous studies explored the self-concept clarity as one of the possible interventions to reduce or prevent body dissatisfaction [36]. Nevertheless, as discussed earlier, reducing body dissatisfaction does not necessarily improve body esteem. As body esteem and body dissatisfaction are constructed independently of each other, implying that body esteem is induced by different factors from those for body dissatisfaction. In addition, Vartanian and Dey [33] argued that adolescents' body image must be understood by studying not only sociocultural factors, but also individual characteristics such as the self-concept clarity.

For many years, body esteem was studied mostly in the Western sample. Recent studies, however, suggest that these issues are also present in other ethnic groups. To our knowledge, there is no study that has examined the relationships among self-concept clarity, tripartite influence, and body esteem, in middle school students in Korea. Therefore, the current study investigates the effects of one internal (self-concept clarity) and three external (tripartite influence from media, parents, and peers) factors that affect adolescents' internalization of the thin-body ideal and body esteem for male and female groups.

As Di Fabio [38] argued, there is a need to focus on crucial psychological aspects to concretely progress toward sustainability and sustainable development. The current study aims to explore factors that are malleable and that can be enhanced with specific training such as self-concept clarity and thin body internalization. These resources are useful and appropriate for interventions because they induce consistent and comprehensive self-recognition in early adolescence. These factors will reduce body comparative behaviors, which in turn can be expected to facilitate a positive recognition of one's own 
body and sustainable individual growth. Specifically, based on previous research, we hypothesize that both internal and external factors have direct and indirect relations with body esteem. We hypothesize that girls perceive greater tripartite influence than boys. In addition, we also expect both internal and external factors to be related to body esteem via a mediator (i.e., internalization) [39], and the magnitude and significance to vary across genders. Structural equation modeling (SEM) analyses have been carried out to assess the hypothesized structural relationships based on two sub-samples (males and females).

\section{Methods}

\subsection{Participants}

Participants were 1127 students (Grades 7-9 in the US) from five middle schools in South Korea. Of the 1127 participants in the study, 632 were girls (56.1\%) and 495 were boys (43.9\%). The participants ranged in age from 12 to 15 years $(M=13.14 ; S D=0.93)$.

\subsection{Procedure}

Data were collected in the fall semester in 2018, and we selected the middle schools in order to obtain a set of schools that was as similar as possible to the school demographic characteristics including size (number of students), location, and socioeconomic status indicators. In an effort to find as much a representative sample as possible, we sought a school with students from families of all socioeconomic backgrounds, particularly a distribution that reflected the national socioeconomic distribution. The students were asked to fill out the survey after their parents had provided consent for them to participate in the study. The entire survey was reviewed and approved by a professional panel of school counselors and ethics committee before administration. Among the total of 1152 enrolled students, 25 students declined to participate in the survey; and we excluded their incomplete surveys from the data. In addition, students completed the paper-and-pencil questionnaire in the homeroom classroom under homeroom teacher supervision. The teacher also read aloud the instructions provided by the researchers and was available to clarify or answer students' questions. Finally, students were told not to write their names on the questionnaire for the sake of anonymity.

\subsection{Measures}

Self-concept clarity. To measure self-concept clarity, the self-concept clarity scale (SCCS) [31] was used. The SCCS's reliability and validity with Korean adolescent samples were found to be in the acceptable range in previous studies (e.g., Cronbach's $\alpha>0.80$ ) [40-42]. The scale consisted of 12 items (e.g., In general, I have a clear sense of who I am and what I am) that the respondents rated based on a scale ranging from "definitely disagree" (1) to "definitely agree" (5). Higher scores reflect greater self-concept clarity. For the current sample, the internal consistency of the scale was acceptable (Cronbach's $\alpha=0.85$ ).

Body Esteem. The body-esteem scale (BES) [19] was used in this study. Body esteem refers to one's overall appraisal or evaluation of his or her own body function, ability, and appearance; it is understood that a positive conception towards one's body is related to a higher level of body esteem. The BES's reliability and validity with Korean adolescent samples were found to be in the acceptable range in previous studies (e.g., Cronbach's $\alpha>0.86 \sim 0.88$ ) [43,44]. This scale contains 23 items (e.g., "Other people consider me good looking") that the respondents rated their answers based on a scale ranging from "not at all" (1) to "very true" (4). For the current study, Cronbach's alpha was 0.88.

Internalization. The sociocultural internalization of appearance questionnaire-adolescents (SIAQ-A) [45] was used to assess internalization. The SIAQ-A's reliability and validity with Korean adolescent samples were found to be in the acceptable range in previous studies (e.g., Cronbach's $\alpha$ $>0.79 \sim 0.88)[46,47]$. Five items were used to represent the incorporation of socially defined ideals of attractiveness into one's own self-identity from media (e.g., I would like my body to look like the 
bodies of people in the movies). For the current sample, the internal consistency of the scale was acceptable (Cronbach's $\alpha=0.85$ ).

Sociocultural Influence. To measure the sociocultural influence, 43 items (i.e., 13 for peer, 20 for parental, and 10 for media influence) of the tripartite influence scale-revised ${ }^{6}$ were used. This scale has been reported to have a good reliability with Korean adolescent samples (Cronbach's $\alpha$ range $=0.85 \sim 0.90)[47,48]$. For the current sample, the internal consistency of the scale was acceptable (Cronbach's $\alpha=0.88,0.87$, and 0.85 for peer, parent, and media pressure, respectively).

\subsection{Analysis}

The structural equation modeling (SEM) was used to assess the hypothesized structural relationships across genders. SEM was selected because it has the flexibility to test relationships among latent variables of interest [49]. This is one of the advantages of using SEM over traditional methods such as ANOVA and regression analysis, in that it allows researchers to quantify measurement errors in a separate term, thereby isolating the "true" effects [50]. All analyses have been carried out based on two sub-samples (males and females).

In the first step, we established the initial structural model so as to reflect the partial mediation, with both direct and indirect paths from self-concept clarity and tripartite influence factors to outcome via a mediating variable (i.e., internalization). The second structural model represented the full mediational model, which excluded the direct paths from self-concept clarity and tripartite influence factors to the outcome variable. Two mediational models were tested to compare and derive the best model. The model fit was assessed based on several criteria: The non-normed fit index (NNFI) [51], the comparative fit index (CFI) [52], and the root mean square error of approximation (RMSEA) [53]. Values less than 0.08 for the RMSEA and values close to 0.95 for the NNFI and CFI were used to determine a good-fitting model [54]. All analyses were conducted using AMOS 18 [55].

In the second step, to test the significance of the mediating effects, we used the maximum likelihood bootstrapping with a $95 \%$ confidence interval [56]. This method utilizes repeated sampling from the data set and estimates the indirect effect in each re-sampled data set. Preacher \& Haye's [57] nonparametric bootstrapping analyses were conducted to estimate the standard errors for the resulting sampling distribution.

In the third step, in testing for possible group differences on structural paths, the measurement model for each construct should operate equivalently across different groups (i.e., male and female groups), so that the differences on the structural paths can be meaningfully comparable across different groups [58]. This is called the metric invariance, which is a prerequisite for multigroup SEM. Therefore, the measurement model was constrained for equal corresponding loadings across the groups. After establishing metric invariances for the partial mediating model, each structural path was tested across genders.

\section{Results}

\subsection{Descriptive Statistics}

Descriptive results and correlations among study variables are summarized in Tables 1 and 2. Gender differences in the study variables were analyzed using t-tests. Significant differences were found among all variables. Girls reported higher scores in items related to all three tripartite influence subscales (for peer influence, mean $=3.11$ for girls and mean $=2.24$ for boys, $p<0.05$ ), while boys scored higher on body esteem items (mean $=3.20$ for boys and mean $=2.77$ for girls). This is in line with previous studies. Extant studies have shown that adolescent boys tend to have higher levels of body esteem than girls [20,59]. Significant correlations were found among the study variables in both males and females (i.e., correlation coefficients $r$ ranged from 0.10 to 0.70 for males and 0.14 to 0.68 for females). According to the guidelines of severe nonnormality (i.e., skew $>2$; kurtosis $>7$ ) proposed by West, Finch \& Curran [60] the normality assumption of all the variables was well met. 
Table 1. Descriptive statistics for variables used in the analysis.

\begin{tabular}{ccccc}
\hline & \multicolumn{2}{c}{ Girls $(N=632)$} & \multicolumn{2}{c}{ Boys $(N=495)$} \\
\hline & Mean & $S D$ & Mean & $S D$ \\
\hline Self-concept clarity $^{\alpha}$ & 3.13 & 0.56 & 3.22 & 0.53 \\
Internalization $^{\alpha}$ & 2.79 & 0.87 & 2.07 & 0.80 \\
Media influence $^{\alpha}$ & 2.63 & 0.77 & 2.00 & 0.75 \\
Parent influence $^{\alpha}$ & 2.23 & 0.72 & 1.82 & 0.86 \\
Peer influence $^{\alpha}$ & 3.11 & 0.84 & 2.24 & 0.86 \\
Body esteem $^{\alpha}$ & 2.77 & 0.69 & 3.20 & 0.64 \\
\hline \multicolumn{4}{c}{ Note. $^{\alpha}$ Gender difference is significant at } & \\
\end{tabular}

Table 2. Correlations and descriptive statistics for study variables.

\begin{tabular}{|c|c|c|c|c|c|c|}
\hline $\begin{array}{ll}\text { Boys } & \text { Girls } \\
\end{array}$ & 1 & 2 & 3 & 4 & 5 & 6 \\
\hline 1. Self-concept clarity & - & $-0.30 *$ & $-0.27 *$ & -0.24 * & $-0.14 *$ & $0.37 *$ \\
\hline 2. Internalization & $-0.27 *$ & - & $0.68 *$ & $0.34 *$ & $0.38 *$ & -0.35 * \\
\hline 3. Media influence & -0.28 * & $0.70 *$ & - & $0.37 *$ & $0.40 *$ & -0.23 * \\
\hline 4. Parent influence & -0.13 * & 0.30 * & $0.34 *$ & - & $0.32 *$ & -0.25 * \\
\hline 5. Peer influence & $-0.20 *$ & $0.32 *$ & $0.36^{*}$ & $0.43 *$ & - & -0.20 * \\
\hline 6. Body esteem & $0.41 *$ & $-0.10 *$ & -0.18 * & $-0.18 *$ & $-0.21 *$ & - \\
\hline
\end{tabular}

Note. ${ }^{*} p<0.05$.

\subsection{Testing the Mediational Models}

The results for the two mediational models indicate that both models provided a good fit to the data: The partial mediational model (for females, $\chi^{2}(104)=363.97 ; \mathrm{CFI}=0.950$; NNFI $=0.959$; RMSEA $=0.062$; for males, $\left.\chi^{2}(104)=368.43 ; \mathrm{CFI}=0.958 ; \mathrm{NNFI}=0.951 ; \mathrm{RMSEA}=0.063\right)$ and the full mediational model (for females, $\chi^{2}(108)=399.6$; CFI $=0.906$; NNFI $=0.906$; RMSEA $=0.080$; for males, $\chi^{2}(108)$ $=388.6 ; \mathrm{CFI}=0.916 ; \mathrm{NNFI}=0.907 ; \mathrm{RMSEA}=0.076$ ). A chi-square difference test was conducted to determine the better-fitting model. The chi-square difference test provided support for the partial meditational model and, therefore, it was selected as the final theoretical model. The fit of the final model was deemed acceptable in terms of the three fit indices. Figures 1 and 2 shows the standardized parameter estimates for this model.

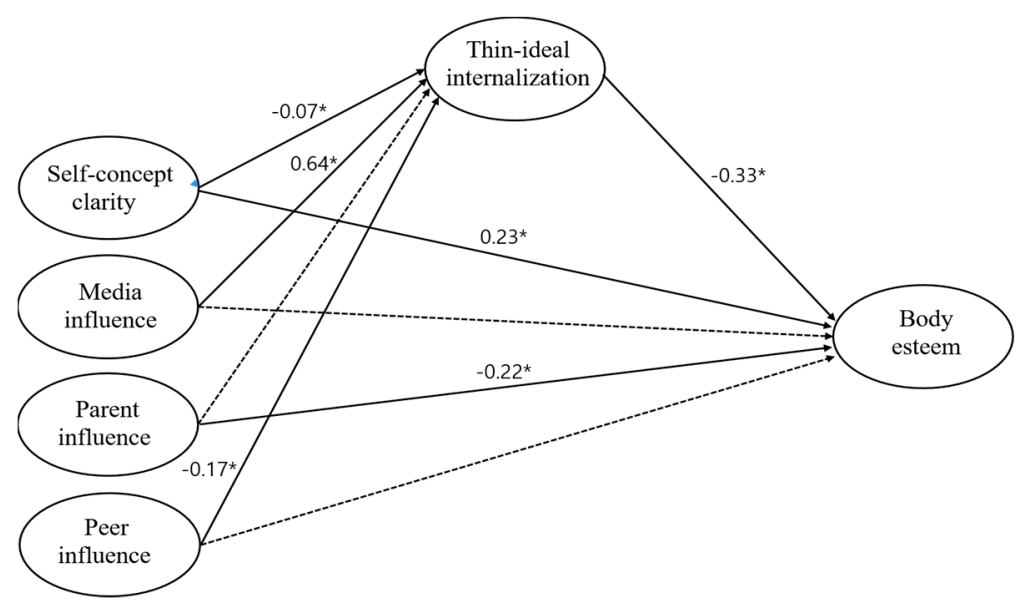

Figure 1. Final model estimation with standardized coefficients (FEMALE). Note. ${ }^{*} p<0.05$; significant path coefficients are shown in bold line. 


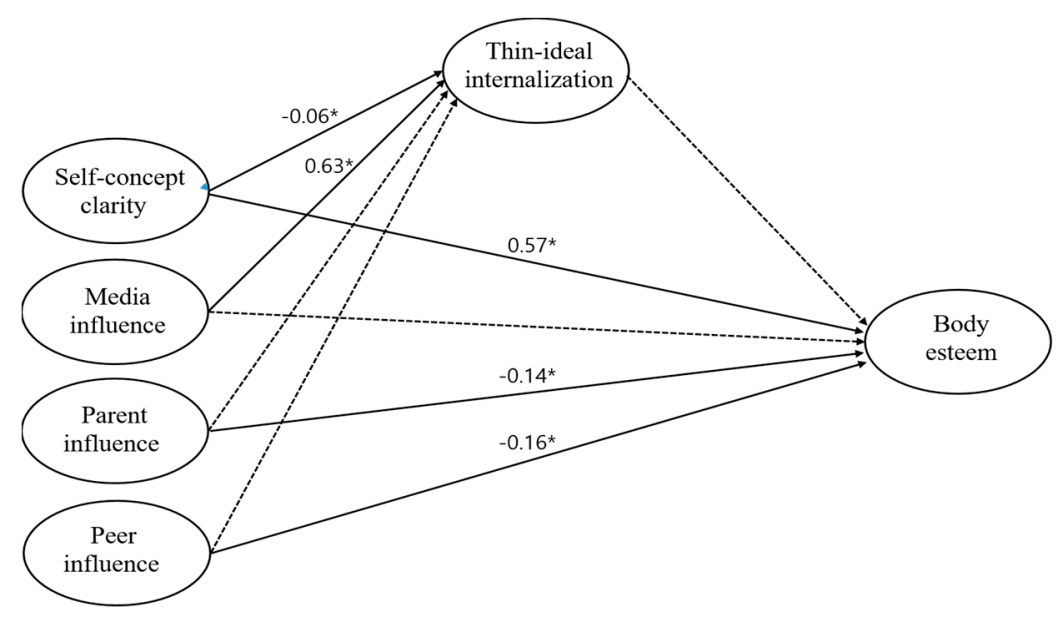

Figure 2. Final model estimation with standardized coefficients (MALE). Note. ${ }^{*} p<0.05$; significant path coefficients are shown in bold line.

According to the bootstrap results (Table 3), the self-concept clarity and two dimensions of the tripartite influence (i.e., media and peer) had significant indirect relationships on body esteem through the mediating variable (i.e., thin body internalization) for girls, but there was no significant indirect relationship found for boys. Specifically, for girls, higher levels of media and peer pressure were positively associated with the internalization of the thin-ideal and, in turn, the internalization of the thin-ideal was negatively associated with body esteem. Contrarily, two dimensions of the tripartite influence (i.e., parent and peers) had a negative direct relationship with body esteem for boys, but only parental pressure had a negative direct relationship with body esteem for girls.

Table 3. Standardized parameter estimates and 95\% confidence intervals (CIs) for indirect effects.

\begin{tabular}{|c|c|c|c|c|}
\hline & \multicolumn{2}{|c|}{ Girls } & \multicolumn{2}{|c|}{ Boys } \\
\hline & $\begin{array}{c}\text { Standardized } \\
\text { Coefficient }\end{array}$ & $\begin{array}{c}\text { 95\% CI (Lower BC, } \\
\text { Upper BC) }\end{array}$ & $\begin{array}{l}\text { Standardized } \\
\text { Coefficient }\end{array}$ & $\begin{array}{c}\text { 95\% CI (Lower BC, } \\
\text { Upper BC) }\end{array}$ \\
\hline $\begin{array}{l}\text { Self-concept clarity } \\
\rightarrow \text { Internalization } \\
\rightarrow \text { Body esteem }\end{array}$ & -0.038 & $(-0.092,-0.006) *$ & 0.049 & $(-0.016,0.342)$ \\
\hline $\begin{array}{l}\text { Media influence } \\
\rightarrow \text { Internalization } \\
\rightarrow \text { Body esteem }\end{array}$ & 0.449 & $(0.156,0.786) *$ & -0.650 & $(-4.729,0.204)$ \\
\hline $\begin{array}{l}\text { Parent influence } \\
\rightarrow \text { Internalization } \\
\rightarrow \text { Body esteem }\end{array}$ & 0.009 & $(-0.018,0.050)$ & -0.011 & $(-0.250,0.016)$ \\
\hline $\begin{aligned} & \text { Peer influence } \\
& \rightarrow \text { Internalization } \\
& \rightarrow \text { Body esteem }\end{aligned}$ & -0.111 & $(-0.060,-0.151) *$ & 0.016 & $(-0.016,0.249)$ \\
\hline
\end{tabular}

Note. $\mathrm{BC}=$ bias corrected; $\mathrm{CI}=$ confidence intervals; 500 bootstrap samples; ${ }^{*}=$ significant bootstrapping; SSC: Self-concept clarity; MI: Media influence; PAI: Parent influence; PEI: Peer influence; INT: Internalization; BES: Body esteem.

In testing for possible group differences on structural paths, the results from the testing of the metric invariance model revealed a well-fitting model $\left(\chi^{2}(210)=760.99, \mathrm{CFI}=0.958\right.$; NNFI $=0.953$; RMSEA $=0.066$ ). After establishing metric invariances for the partial mediating model, each structural path was tested across genders. The results showed that there were gender differences in four paths (see Table 4). Specifically, for the path from self-concept clarity to body esteem, the effect was stronger for boys $(\beta=0.57, p<0.05)$ than for girls $(\beta=0.23, p<0.05)$. 
Table 4. Model comparison (multi-group analysis).

\begin{tabular}{|c|c|c|c|c|c|c|c|c|c|c|c|c|}
\hline Model & Equality Constraints & $x^{2}$ & $d f$ & $p$ & $\Delta \chi^{2}$ & $\Delta d f$ & $\chi^{2}$ Diff Test & CFI & NNFI & SRMR & RMSEA & $(90 \% \mathrm{CI})$ \\
\hline baseline model & & 732.394 & 208 & 0.000 & & & & 0.950 & 0.952 & 0.048 & 0.067 & $(0.062,0.072)$ \\
\hline baseline model(male) & & 368.427 & 104 & 0.000 & & & & 0.958 & 0.951 & 0.045 & 0.063 & $(0.056,0.071)$ \\
\hline baseline model(female) & & 363.967 & 104 & 0.000 & & & & 0.950 & 0.959 & 0.052 & 0.062 & $(0.054,0.070)$ \\
\hline metric invariance model & & 760.989 & 219 & 0.000 & 28.595 & 11 & non-sig & 0.958 & 0.953 & 0.051 & 0.066 & $(0.061,0.072)$ \\
\hline structural invariance model1 & $\mathrm{SSC} \rightarrow \mathrm{INT}$ & 761.074 & 220 & 0.000 & 0.085 & 1 & non-sig & 0.938 & 0.924 & 0.051 & 0.066 & $(0.061,0.071)$ \\
\hline structural invariance model2 & $\mathrm{MI} \rightarrow \mathrm{INT}$ & 761.037 & 220 & 0.000 & 0.048 & 1 & non-sig & 0.938 & 0.924 & 0.051 & 0.066 & $(0.061,0.071)$ \\
\hline structural invariance model3 & $\mathrm{PAI} \rightarrow \mathrm{INT}$ & 761.948 & 220 & 0.000 & 0.959 & 1 & non-sig & 0.938 & 0.924 & 0.051 & 0.066 & $(0.061,0.071)$ \\
\hline structural invariance model 4 & $\mathrm{PEI} \rightarrow \mathrm{INT}$ & 769.201 & 220 & 0.000 & 8.212 & 1 & sig & 0.948 & 0.944 & 0.051 & 0.066 & $(0.061,0.071)$ \\
\hline structural invariance model5 & $\mathrm{SSC} \rightarrow \mathrm{BES}$ & 769.433 & 220 & 0.000 & 8.444 & 1 & sig & 0.957 & 0.953 & 0.052 & 0.067 & $(0.062,0.072)$ \\
\hline structural invariance model6 & $\mathrm{MI} \rightarrow \mathrm{BES}$ & 761.361 & 220 & 0.000 & 0.372 & 1 & non-sig & 0.938 & 0.924 & 0.051 & 0.066 & $(0.061,0.071)$ \\
\hline structural invariance model7 & $\mathrm{PAI} \rightarrow \mathrm{BES}$ & 761.311 & 220 & 0.000 & 0.322 & 1 & non-sig & 0.938 & 0.924 & 0.051 & 0.066 & $(0.061,0.071)$ \\
\hline structural invariance model8 & $\mathrm{PEI} \rightarrow \mathrm{BES}$ & 765.684 & 220 & 0.000 & 4.695 & 1 & $\operatorname{sig}$ & 0.958 & 0.953 & 0.052 & 0.067 & $(0.061,0.072)$ \\
\hline structural invariance model9 & $\mathrm{INT} \rightarrow \mathrm{BES}$ & 770.870 & 220 & 0.000 & 9.881 & 1 & sig & 0.957 & 0.952 & 0.052 & 0.067 & $(0.062,0.072)$ \\
\hline structural invariance model10 & all path & 788.379 & 228 & 0.000 & 27.390 & 9 & non-sig & 0.936 & 0.924 & 0.053 & 0.066 & $(0.061,0.071)$ \\
\hline final model * & & 762.943 & 225 & 0.000 & 1.954 & 6 & non-sig & 0.959 & 0.956 & 0.051 & 0.065 & $(0.060,0.070)$ \\
\hline
\end{tabular}




\section{Discussion}

Adolescents lack a firm identity, go through frequent changes, experience confusion, and display comparative behaviors [61,62]. It is therefore crucial for them to establish a consistent and clear self-concept that is not based upon their appearance or body image. Particularly, self-concept clarity is far more significant, as it has been reported to positively affect various aspects of mental health, including self-esteem, positive emotions [31], subjective well-being, and psychological adjustment [63]. Therefore, the current study examined how one internal (self-concept clarity) and three external (tripartite influence from media, parents, and peers) factors are associated with adolescents' internalization of the thin-body ideal and body esteem. The current findings also identified self-concept clarity as a powerful factor that is positively related with body esteem for both adolescent girls and boys.

According to the results, the direct positive association of self-concept clarity with body esteem was revealed to be stronger for the adolescent boys than for the girls, but its indirect association with body esteem was significant only for the girls. These findings are consistent with previous research. Kil and Oh's study [64] on Korean college students showed that male students had a clearer self-concept than females, while females displayed stronger narcissistic characteristics such as ostentation and vanity. Also, in the same vein, Wee [47] argued that Korean female adolescents have a stronger tendency to recognize, accept, and internalize sociocultural values and have lower body satisfaction than Korean male adolescents. Cho and Lee's study [41] on the effects of self-concept clarity on the disordered eating behaviors by Korean females in their teens and 20s found that a less clear self-concept increased body comparative behaviors and body dissatisfaction.

Among the sociocultural pressures (tripartite influence), media pressure was found to be the strongest factor enhancing internalization for both adolescent girls and boys. The internalization of ideals refers to adopting social ideals presented through media as an individual standard [65]. As these ideals, which are spread through mass media in both traditional forms and especially internet-based SNS etc., are usually unrealistic, research into body image has suggested that their internalization results in a discrepancy between actual and ideal body image, leading to low body esteem [2,23,66,67]. Furthermore, the current finding found gender differences in the relation of internalization with body esteem. According to the results, the internalization of ideals mediated between self-concept clarity, media pressure, and body esteem for girls only, whereas it did not have a significant relation with body esteem for boys. These results imply that although the media have a significant impact on the internalization of an idealized body image [23], the gender differences in the self-concept and individual characteristics also constitute a major factor exerting complex and varied influences on the relation between internalization and body esteem. Overall, internalization enhanced by media pressure was the biggest risk factor that lowers body esteem for adolescent girls.

In addition, among the three types of sociocultural pressure (tripartite influence), parental pressure was found to be negatively associated with body esteem for both genders. These results support the findings of previous studies. Wee [47] examined the effect of parents on the body image of adolescents and found that even for children of average weight, the parents tended to depict their daughters as fat and their sons as thin. Children were found to be sensitive to their parents' judgment of their bodies and, thus, parents' perception of their children as being overweight was associated with the female children's low self-esteem. As body esteem is known as one of the primary constructs of self-esteem [59], these results indicated the negative influence of parents' pressure on adolescents' body esteem. Stice [68] also claimed that the sociocultural influence on female adolescents' body dissatisfaction is not only limited to the media, but that parents and peers also enhance their body dissatisfaction individually and conjunctively, regardless of their actual body type. Lastly, among the three types of sociocultural pressure, peer pressure was found to lower body esteem differentially across genders. Peer pressure was directly associated with body esteem for boys, but was indirectly associated with body esteem via internalization for girls. These results support the findings of previous studies which reported a positive relation between peer pressure for thinness and body 
dissatisfaction [69-72]. Choo [73] argued that the individuals' body satisfaction is not determined by objective body measurements, but by sociocultural criteria, and that the evaluation of one's own body is based on one's interactions with others. Gondol et al. [69] showed that peer pressure for thinness exacerbated female adolescents' body dissatisfaction. Helfert and Warschburger [74] reported that peers had an influence on different weight concerns for different gender-muscle concerns for male adolescents and weight concerns for female adolescents.

This study has several limitations. First, this study relied on self-reported measures. Future research is needed to include observational data as well. Second, the participants consisted of only early adolescents and has been collected in South Korea, limiting the generalizability of the results. Thus, further research is required to investigate whether the results are replicable with late adolescents from different countries. In a further study, a comparison of western countries and eastern countries in terms of the relationship between body esteem and the predictor variables could also be worth exploring. Third, as adolescents' body esteem can vary depending on their weight, data on their BMI must be collected and analyzed. Shriver et al. [75] studied 3rd graders' body esteem and argued in favor of a gender difference concerning the effect of weight status on body esteem overall. That is, the male students with different weight statuses did not show any statistically significant differences in their body esteem, while the body esteem of overweight or obese female students was more negative than that of those with normal weight status. Therefore, future research also needs to examine the interaction between gender and BMI, in order to obtain a more comprehensive understanding of self-concept clarity and body esteem.

In conclusion, the current study findings contribute to our understanding of the psychological mechanisms of positive body recognition through the investigation of adolescents' self-concept clarity as an internal protective factor. For adolescent girls, both self-concept clarity and two dimensions of the tripartite influence (media and peer) were associated indirectly with body esteem via thin body internalization. For adolescent boys, self-concept clarity, parental and peer influences were associated directly with body esteem. The current study finding is important in establishing the psychology of sustainability and sustainable development as a research area, rather than one that only provides theoretical perspectives. In this vein, this study can help recognize and integrate the value of psychology and psychological approaches in the construction of processes linked to positive recognition of one's own body and sustainable individual growth. Future experimental research should explore other personality traits in order to understand this complex relation between body esteem and mental health. We also suggest that programs should be developed for building positive body image perception, with personality taken into account, and their effectiveness investigated.

Author Contributions: Conceptualization, formal analysis, funding acquisition, methodology, writing-original draft, S.Y.; data curation, investigation, validation, writing-review and editing, K.S.

Funding: This work was supported by the Ministry of Education of the Republic of Korea and the National Research Foundation of Korea (NRF-2016S1A5A2A01022886).

Conflicts of Interest: The authors declare that they have no conflict of interest.

\section{References}

1. Harter, S.; Leahy, R.L. The construction of the self: A developmental perspective. J. Cogn. Psychother. 2001, 15, 383-384. [CrossRef]

2. You, S.; Shin, K.; Kim, E.K. The effects of sociocultural pressures and exercise frequency on the body esteem of adolescent girls in Korea. J. Child Fam. Stud. 2018, 27, 26-33. [CrossRef]

3. Kennedy, A.K.; Schneiderman, J.U.; Winter, V.R. Association of body weight perception and unhealthy weight control behaviors in adolescence. Child. Youth Serv. Rev. 2019, 96, 250-254. [CrossRef]

4. Izydorczyk, B.; Sitnik-Warchulska, K. Sociocultural appearance standards and risk factors for eating disorders in adolescents and women of various ages. Front. Psychol. 2018, 9, 429. [CrossRef] [PubMed] 
5. Rodgers, R.F.; McLean, S.A.; Marques, M.; Dunstan, C.J.; Paxton, S.J. Trajectories of body dissatisfaction and dietary restriction in early adolescent girls: A latent class growth analysis. J. Youth Adolesc. 2016, 45, 1664-1677. [CrossRef]

6. Koo, J.; Suk, E. Why Korean university students are less happy than U.S. counterparts? The role of relative extrinsic value orientation, social support and social comparison. Korean J. Soc. Personal. Psychol. 2015, 29, 63-83.

7. Seol, K.; Park, S.Y.; Park, J.E. Materialism, lookism and disordered eating symptoms among young adult women: Social comparison and body dissatisfaction as mediators. Korean J. Couns. Psychother. 2016, 28, 875-896. [CrossRef]

8. Jung, J.; Forbes, G.B.; Lee, Y. Body dissatisfaction and disordered eating among early adolescents from Korea and the US. Sex Roles 2009, 61, 42-54. [CrossRef]

9. You, S.; Shin, K.; Kim, A.Y. Body image, self-esteem, and depression in Korean adolescents. Child Indic. Res. 2017, 10, 231-245. [CrossRef]

10. Ha, M.; Kim, J.-H. The relationship between fear of physical unattractiveness and depression mediated by body satisfaction and dependence for young adolescents. Asian J. Educ. 2013, 14, 345-368.

11. Swami, V.; Weis, L.; Barron, D.; Furnham, A. Positive body image is positively associated with hedonic(emotional) and eudaimonic(psychological and social) well-being in British adults. J. Soc. Psychol. 2018, 158, 541-552. [CrossRef] [PubMed]

12. Tylka, T.L.; Wood-Barcalow, N.L. What is and what is not positive body image? Conceptual foundations and construct definition. Body Image 2015, 14, 118-129. [CrossRef] [PubMed]

13. Tylka, T.L. Positive psychology perspectives on body image. In Body Image: A Handbook of Science, Practice, and Prevention, 2nd ed.; Cash, T.F., Smolak, L., Eds.; Guilford Press: New York, NY, USA, 2011; pp. 56-64.

14. Tylka, T.L.; wood-Barcalow, N.L. The body Appreciation Scale-2: Item refinement and psychometric evaluation. Body Image 2015, 12, 53-67. [CrossRef] [PubMed]

15. Wood-Barcalow, NL.; Tylka, T.L.; Augustus-Horvath, C.L. "But I like my body": Positive body image characteristics and a holistic model for young-adult women. Body Image 2010, 7, 106-116. [CrossRef]

16. Franzoi, S.L.; Shields, S.A. The Body Esteem Scale: Multidimensional structure and sex differences in a college population. J. Personal. Assess. 1984, 48, 173-178. [CrossRef]

17. Nelson, S.C.; Kling, J.; Wängqvist, M.; Frisén, A.; Syed, M. Identity and the body: Trajectories of body esteem from adolescence to emerging adulthood. Dev. Psychol. 2018, 54, 1159. [CrossRef] [PubMed]

18. Taylor, Z.E.; Doane, L.D.; Eisenberg, N. Transitioning from high school to college: Relations of social support, ego-resiliency, and maladjustment during emerging adulthood. Emerg. Adulthood 2013, 2, 105-114. [CrossRef]

19. Mendelson, B.K.; Mendelson, M.J.; White, D.R. Body-esteem scale for adolescents and adults. J. Personal. Assess. 2001, 76, 90-106. [CrossRef] [PubMed]

20. Kim, K.-H.; Kim, J.-S. The effects of a narcissistic tendency and body esteem on beauty management and hair behavior. J. Korean Soc. Knit Des. 2015, 13, 38-44.

21. Ormsby, H.; Owen, A.L.; Bhogal, M.S. A brief report on the associations amongst social media use, gender, and body esteem in a UK student sample. Curr. Psychol. 2018, 1-5. [CrossRef]

22. Valois, D.D.; Davis, C.G.; Buchholz, A.; Obeid, N.; Henderson, K.; Flament, M.; Goldfield, G.S. Effects of weight teasing and gender on body esteem in youth: A longitudinal analysis from the REAL study. Body Image 2019, 29, 65-73. [CrossRef] [PubMed]

23. Barlett, C.P.; Vowels, C.L.; Saucier, D.A. Meta-analyses of the effects of media images on men's body-image concerns. J. Soc. Clin. Psychol. 2008, 27, 279-310. [CrossRef]

24. Shin, K.; You, S.; Kim, E. Sociocultural pressure, internalization, BMI, exercise, and body dissatisfaction in Korean female college students. J. Health Psychol. 2017, 22, 1712-1720. [CrossRef]

25. Ho, S.S.; Lee, E.W.J.; Liao, Y. Social network sites, friends, and celebrities: The roles of social comparison and celebrity involvement in adolescents' body image dissatisfaction. Soc. Media Soc. 2016, 2, 1-11. [CrossRef]

26. Lee, M.; Lee, H.H. Objective versus subjective comparisons of body size against thin media models, media pressures, internalization, and body satisfaction. Soc. Sci. J. 2019, 1-9, in press. [CrossRef]

27. Lee, H.R.; Lee, H.E.; Choi, J.; Kim, J.H.; Han, H.L. Social media use, body image, and psychological well-being: A cross-cultural comparison of Korea and the United States. J. Health Commun. 2014, 19, 1343-1358. [CrossRef] 
28. Kim, N.-H.; Kim, K.H.; Kim, S.-H. The influence of sociocultural pressure of being slim on restrained eating attitude and eating behavior: The effect of body dissatisfaction and mindfulness. Korean J. Helath Psychol. 2015, 23, 527-546.

29. Kim, H.; Lee, J. A Structural analysis of socially prescribed perfectionism, social comparison orientation, body comparison, body dissatisfaction perceived by female high school students. Soc. Sci. Study 2016, 42, 253-276.

30. Campbell, J.D. Self-esteem and clarity of self-concept. J. Personal. Soc. Psychol. 1990, 59, 538-549. [CrossRef]

31. Campbell, J.D.; Trapnell, P.D.; Heine, S.J.; Katz, I.M.; Lavallee, L.F.; Lehman, D.R. Self-concept clarity: Measurement, personality correlates, and cultural boundaries. J. Personal. Soc. Psychol. 1996, 70, 141-156. [CrossRef]

32. Kang, S.-Y.; Hong, H.Y. The relations between career's overt, covert narcissism and aggressiveness: Moderating role of self-concept clarity. Korean J. Interdiscip. Ther. 2012, 4, 25-51.

33. Vartanian, L.R.; Dey, S. Self-concept clarity, thin-ideal internalization, and appearance-related social comparison as predictors of body dissatisfaction. Body Image 2013, 10, 495-500. [CrossRef] [PubMed]

34. Vartanian, L.R. When the body defines the self: Self-concept clarity, internalization, and body image. J. Soc. Clin. Psychol. 2009, 28, 94-126. [CrossRef]

35. Vartanian, L.R.; Hayward, L.E.; Smyth, J.M.; Paxton, S.J.; Touyz, S.W. Risk and resiliency factors related to body dissatisfaction and disordered eating: The identity disruption model. Int. J. Eat. Disord. 2018, 51, 322-330. [CrossRef]

36. Vartanian, L.R.; Froreich, F.V.; Smyth, J.M. A serial mediation model testing early adversity, self-concept clarity, and thin-ideal internalization as predictors of body dissatisfaction. Body Image 2016, 19, 98-103. [CrossRef]

37. Jeon, S.B. The Relation between Sociocultural Pressures and the Internalization of the Thin Ideal in Female College Students: Moderation Effects of Self-Concept Clarity and Self-Esteem. Master's Thesis, Ewha Womans University, Seoul, Korea, 2012.

38. Di Fabio, A.; Rosen, M.A. Opening the black box of psychological processes in the science of sustainable development: A new frontier. Eur. J. Sustain. Dev. Res. 2018, 2, 47. [CrossRef]

39. Flament, M.F.; Hill, E.M.; Buchholz, A.; Henderson, K.; Tasca, G.A.; Goldfield, G. Internalization of the thin and muscular body ideal and disordered eating in adolescence: The mediation effects of body esteem. Body Image 2012, 9, 68-75. [CrossRef] [PubMed]

40. Choi, B.-O. The mediating effects of maladaptive perfectionism and self-concept clarity between narcissistic vulnerability and disordered eating behaviors. Korean J. Youth Stud. 2016, 23, 195-217. [CrossRef]

41. Cho, K.-H.; Lee, B.-K. The influence of self-concept clarity on disordered eating behaviors: The mediating effects of physical comparison and body dissatisfaction. Korean J. Helath Psychol. 2015, 20, 469-484.

42. Lim, A. Relationships of narcissism and self-concept clarity with anger behavior among adolescents. Asian J. Educ. 2011, 12, 305-325.

43. Lee, E.M.; Kim, Y.J. Effect of body figure discrepancy, body esteem, interpersonal stress, and sociocultural attitude toward appearance on social pressure related to appearance perceived by high school students. Stress 2017, 25, 37-43. [CrossRef]

44. Jung, S.Y. The effect of female adolescent body-relation variables, body esteem, and self-control on eating disorder behavior. J. Korean Data Inf. Sci. Soc. 2017, 28, 1403-1414. [CrossRef]

45. Keery, H.; Shroff, H.; Thompson, J.K.; Wertheim, E.; Smolak, L. The Sociocultural Internalization of Appearance Questionnaire-Adolescents (SIAQ-A): Psychometric analysis and normative data for three countries. Eat. Weight Disord. Stud. Anorex. Bulim. Obes. 2004, 9, 56-61. [CrossRef]

46. Park, J.-I.; Yoo, J.-M.; Kim, C.-S. The effect of overexposure in the mass media's to emphasize the appearance on body images and self-esteem of female adolescents. Korean J. Youth Stud. 2016, 23, 167-187. [CrossRef]

47. Wee, E.A. Study on differences in body comparison, body satisfaction, and appearance management behaviors according to social cultural attitudes toward appearance among adolescents in Gwangju and Jeonnam province-By sex and age. Korean Home Econ. Educ. Assoc. 2015, 27, 13-29.

48. Park, W.; Epstein, N.B. The longitudinal causal directionality between body image distress and self-esteem among Korean adolescents: The moderating effect of relationships with parents. J. Adolesc. 2013, 36, 403-411. [CrossRef]

49. Kline, R.B. Structural Equation Modeling; Guilford Press: New York, NY, USA, 1998. 
50. McDonald, R.P.; Ho, M.H.R. Principles and practice in reporting structural equation analyses. Psychol. Methods 2002, 7, 64-82. [CrossRef]

51. Bentler, P.M.; Bonett, D.G. Significance tests and goodness-of-fit in the analysis of covariance structures. Psychol. Bull. 1980, 88, 588-606. [CrossRef]

52. Bentler, P.M. Comparative fit indexes in structural models. Psychol. Bull. 1990, 107, 238-246. [CrossRef]

53. Steiger, J.H.; Lind, J.M. Statistically based tests for the number of common factors. In Proceedings of the Annual Meeting of the Psychometric Society, Iowa City, IA, USA, 30 May 1980.

54. Hu, L.T.; Bentler, P.M. Cutoff criteria for fit indexes in covariance structure analysis: Conventional criteria versus new alternatives. Struct. Equ. Model. 1999, 1, 1-55. [CrossRef]

55. Arbuckle, J.L. Amos 5.0; SPSS: Chicago, IL, USA, 2003.

56. Shrout, P.; Bolger, N. Mediation in experimental and nonexperimental studies: New procedures and recommendations. Psychol. Methods 2002, 7, 422-445. [CrossRef]

57. Preacher, K.J.; Hayes, A.F. Asymptotic and resampling strategies for assessing and comparing indirect effects in multiple mediator models. Behav. Res. Methods 2008, 40, 879-891. [CrossRef]

58. Steenkamp, J.B.E.; Baumgartner, H. Assessing measurement invariance in cross-national consumer research. J. Consum. Res. 1998, 25, 78-90. [CrossRef]

59. Gim, W.-S. Korean Overall Body Esteem Scale (KOBES): Development, validation, and gender differences. Korean J. Women Psychol. 2007, 12, 231-253.

60. West, S.G.; Finch, J.F.; Curran, P.J. Structural equation models with nonnormal variables: Problems and remedies. In Structural Equation Modeling: Concepts, Issues and Applications; Hoyle, R.H., Ed.; Sage: Thousand Oaks, CA, USA, 1995; pp. 56-75.

61. Zsakai, A.; Karkus, Z.; Utczas, K.; Bodzsar, E.B. Body structure and physical self-concept in early adolescence. J. Early Adolesc. 2017, 37, 316-338. [CrossRef]

62. Kroger, J.; Martinussen, M.; Marcia, J.E. Identity status change during adolescence and young adulthood: A meta-analysis. J. Adolesc. 2010, 33, 683-698. [CrossRef]

63. Parise, M.; Canzi, E.; Olivari, M.G.; Ferrari, L. Self-concept clarity and psychological adjustment in adolescence: The mediating role of emotion regulation. Personal. Individ. Differ. 2019, 138, 363-365. [CrossRef]

64. Kil, J.H.; Oh, K.J. The effect of narcissistic features and self-concept clarity on aggression. Korean J. Clin. Psychol. 2008, 27, 911-924.

65. Kleemans, M.; Daalmans, S.; Carbaat, I.; Anschütz, D. Picture perfect: The direct effect of manipulated Instagram photos on body image in adolescent girls. Media Psychol. 2018, 21, 93-110. [CrossRef]

66. Nichols, T.E.; Damiano, S.R.; Gregg, K.; Wertheim, E.H.; Paxton, S.J. Psychological predictors of body image attitudes and concerns in young children. Body Image 2018, 27, 10-20. [CrossRef]

67. Obeid, N.; Norris, M.L.; Buchholz, A.; Henderson, K.A.; Goldfield, G.; Bedford, S. Socioemotional predictors of body esteem in adolescent males. Psychol Men Masc. 2018, 19, 439-445. [CrossRef]

68. Stice, E. A prospective test of the dual-pathway model of bulimic pathology: Mediating effects of dieting and negative effect. J. Abnorm. Psychol. 2001, 110, 124-135. [CrossRef]

69. Gondoli, D.M.; Corning, A.F.; Salafia EH, B.; Bucchianeri, M.M.; Fitzsimmons, E.E. Heterosocial involvement, peer pressure for thinness, and body dissatisfaction among young adolescent girls. Body Image 2011, 8 , 143-148. [CrossRef]

70. Tatangelo, G.L.; Ricciardelli, L.A. Children's body image and social comparisons with peers and the media. J. Health Psychol. 2017, 22, 776-787. [CrossRef]

71. Carey, R.N.; Donaghue, N.; Broderick, P. Peer culture and body image concern among Australian adolescent girls: A hierarchical linear modelling analysis. Sex Roles 2013, 69, 250-263. [CrossRef]

72. Romo, L.F.; Mireles-Rios, R.; Hurtado, A. Cultural, media, and peer influences on body beauty perceptions of Mexican American adolescent girls. J. Adolesc. Res. 2016, 31, 474-501. [CrossRef]

73. Choo, T.G. Multiple body-image and clothing benefit sought according to body-cathexis. Fashion Text. Res. J. 2002, 4, 376-382. 
74. Helfert, S.; Warschburger, P. A prospective study on the impact of peer and parental pressure on body dissatisfaction in adolescent girls and boys. Body Image 2011, 8, 101-109. [CrossRef] [PubMed]

75. Shriver, L.H.; Harrist, A.W.; Page, M.; Hubbs-Tait, L.; Moulton, M.; Topham, G. Differences in body esteem by weight status, gender, and physical activity among young elementary school-aged children. Body Image 2013, 10, 78-84. [CrossRef] [PubMed] 